\title{
Evaluation of corrective measures implemented for the preventive conservation of fresco paintings in Ariadne's house (Pompeii, Italy)
}

Paloma Merello ${ }^{1,2+}$, Fernando-Juan García-Diego ${ }^{1,3^{*}+}$ and Manuel Zarzo ${ }^{4 \dagger}$

\begin{abstract}
Background: A microclimate monitoring study was conducted in 2008 aimed at assessing the conservation risks affecting the valuable wall paintings decorating Ariadne's House (Pompeii, Italy). It was found that thermohygrometric conditions were very unfavorable for the conservation of frescoes. As a result, it was decided to implement corrective measures, and the transparent polycarbonate sheets covering three rooms (one of them delimited by four walls and the others composed of three walls) were replaced by opaque roofs. In order to examine the effectiveness of this measure, the same monitoring system comprised by 26 thermohygrometric probes was installed again in summer 2010. Data recorded in 2008 and 2010 were compared.

Results: Microclimate conditions were also monitored in a control room with the same roof in both years. The average temperature in this room was lower in 2010, and it was decided to consider a time frame of 18 summer days with the same mean temperature in both years. In the rooms with three walls, the statistical analysis revealed that the diurnal maximum temperature decreased about $3.5^{\circ} \mathrm{C}$ due to the roof change, and the minimum temperature increased $0.5^{\circ} \mathrm{C}$. As a result, the daily thermohygrometric variations resulted less pronounced in 2010, with a reduction of approximately $4^{\circ} \mathrm{C}$, which is favorable for the preservation of mural paintings. In the room with four walls, the daily fluctuations also decreased about $4^{\circ} \mathrm{C}$. Based on the results, other alternative actions are discussed aimed at improving the conservation conditions of wall paintings.
\end{abstract}

Conclusions: The roof change has reduced the most unfavorable thermohygrometric conditions affecting the mural paintings, but additional actions should be adopted for a long term preservation of Pompeian frescoes.

Keywords: Microclimate monitoring, Pompeii, Archaeological preservation, Temperature and relative humidity sensors

\section{Background}

The long-term preservation of wall paintings in open-air sites or semi-confined environments is a challenge due to the difficulty in providing optimum ambient conditions. In such cases, the deterioration process of paintings is determined by many factors such as petrographical and chemical characteristics of the materials, presence of mineral salts

\footnotetext{
* Correspondence: fjgarcid@upvnet.upv.es

${ }^{\dagger}$ Equal contributors

'Department of Applied Physics (UD Agriculture Engineering), Universitat Politècnica de València, Camino de Vera s/n, Valencia 46022, Spain

${ }^{3}$ Center of Physical Technologies, Associated Unit ICMM-CSIC/UPV,

Universitat Politècnica de València, Av de los Naranjos s/n, Valencia 46022,

Spain

Full list of author information is available at the end of the article
}

and organic substances on the surfaces, air pollution, sunlight, heating, water content of the surface, etc. [1].

Weathering and disintegration of buildings, masonries and artifacts, as a result of salt efflorescence effects, have been widely studied. Rocks undergo deterioration processes due to temperature changes because most salts have high coefficients of volumetric expansion [2]. Moisture availability and insolation are also climatic variables affecting weathering [3]. Nonetheless, reported evidence indicates that the atmosphere has little corrosive effect on stone in the absence of water. Thus, it is important to monitor the presence of rainwater when assessing the damages caused by weathering in materials of different compositions [4-7]. Wide diurnal temperature fluctuations, 
sun intensity and sporadic heavy rain showers are the propelling factors for the chemical weathering [8].

Wall paintings are very sensitive to multiple factors such as (i) climatic conditions, especially temperature and humidity $[9,10]$, (ii) presence of soluble salts, (iii) microbiological activity, and (iv) external factors like vandalism or tourism [10]. Indoor environments are more appropriate for the conservation of wall paintings because rainwater is rarely a problem and climatic conditions can be controlled. Many works have monitored thermohygrometric parameters inside museums for the preventive conservation of their collections [11-13] as well as in churches [14-17], but few studies have characterized ambient conditions in semi-confined [18] or open-air archaeological sites $[10,19]$.

The house of Ariadne or dei capitelli colorati (of the colored capitals) is one of the most interesting places in ancient Pompeii (Italy). It is located at less than $100 \mathrm{~m}$ from the forum (Regio VII, insula 4) and presents a surface of $1,700 \mathrm{~m}^{2}$ [20], being one of the largest domus of Pompeian architecture. A 3-D view of the place obtained from a photogrametric scan of the whole ruins [21] shows the remarkable quality of some wall paintings. Detailed pictures of all lodgings in Ariadne's house are available [22].

Although most interior walls were originally ornamented with frescoes, the paintings have suffered severe damages since the excavation of Ariadne's house in 1832-1835. At present, original frescoes are only conserved in three rooms that were sheltered with transparent polycarbonate sheets in the 1970s (coded as 1-3 in Figure 1), and in one additional lodging (room 4, apsidal exedra) that was covered in the 1950s with a roof of ceramic tiles (see [22], web link to room number 29). Room 3 (exedra, coded as lodging 18 in [22]) displays a mosaic of Hellenistic inspiration on the floor $(84 \times 77 \mathrm{~cm})$ protected with a glass box. The mosaic is probably from the second century $\mathrm{BC}$, and the rest of the floor is paved with tiles of a different style (first century $\mathrm{AD}$ ). Room 1 (west side of atrium, lodging 6 in [22]) is delimited by three walls, as well as rooms 1 and 4 . By contrast, room 2 (oecus, coded as 12 in [22]) is composed of four walls.

Mural paintings of Ariadne's house have undergone deterioration processes in the last decades, and a research project was launched in 2008 to assess their conservation state by means of microclimate monitoring, thermography, study of materials, solar radiation, characterization of salt efflorescence, etc. [23]. With respect to the microclimate monitoring, a set of 26 thermohygrometric probes were installed in July 2008 inside the covered rooms (Table 1). Each probe was composed of one relative humidity (RH) data-logger and one temperature data-logger. It was found that the transparent roofs produced an unfavorable greenhouse effect causing excessive temperatures, particularly in summer [24]. As a result, the covering of rooms 1-3 was replaced in December 2009 by undulating opaque red roof sheets made of fiber cement with a thickness of about $6 \mathrm{~mm}$, model ColorAGRI ${ }^{\odot}$ rosso of Edilit SpA (Padova, Italy) [25].

Structural details about the initial roof in rooms 1 and 3 can be seen in [22], following the link to lodgings 6 $\left(1^{\text {st }}\right.$ and $3^{\text {rd }}$ pictures $)$ and 18 ( $2^{\text {nd }}$ picture). The photographs were taken in March 2009 and show the roof slope as well as the metallic structure supporting the polycarbonate sheets. The water drainage gutter and downspout can also be observed. The uniform height of walls propitiated the roof installation directly fixed to the room upper perimeter (see p. 97 of [26]), leaving a negligible ventilation space through the roof borders (less than $5 \mathrm{~cm}$ between the shelter and wall top). Such reduced space is not a problem in this case because rooms 1 and 3 are composed of three walls, which allows an appropriate ventilation. In room 2, the initial roof was also directly resting on the top of the four walls delimiting this lodging as shown in [22], following the link to lodgings $12\left(12^{\text {th }}\right.$ picture $)$ and 13 ( $5^{\text {th }}$ picture).

The roof change of room 1 performed at the end of 2009 is clearly illustrated by comparing the $3^{\text {rd }}$ picture of lodging 6 [22] with a photograph of this room taken in 2010 [23]. The latter shows that three supporting metal square tubes were installed perpendicular to the existing ones to fix conveniently the fiber cement sheets. It can also be noticed in this picture that the roof is not perfectly sealed to the wall borders, allowing certain ventilation. The distance between the wall top and the sheets is about $10 \mathrm{~cm}$. Exhaustive details concerning the design of complex shelters mounted on open-air archaeological sites are described for the Villa Arianna at Castellammare di Stabia (see [26], pp. 307-312) and Punta d'Alaca in the Italian island of Vivara (see [26], pp. 319-323). A comprehensive description of the whole covering project is not addressed here because the shelters are relatively simple and the pictures in [22] provide clear information.

In order to assess the effectiveness of the roof change, the data-loggers used in the previous study [24] were installed in the same locations in summer 2010. The present work performs a comparative statistical analysis of data recorded in 2008 and 2010 (summer periods) aimed at evaluating the effect of roof change on the microclimate conditions surrounding the valuable fresco paintings. Results provide guidelines for additional corrective measures.

\section{Results and discussion Monitoring periods}

As the summer season is the most hostile for the conservation of outdoor wall paintings given the high temperatures and daily variations, it was decided to conduct the 


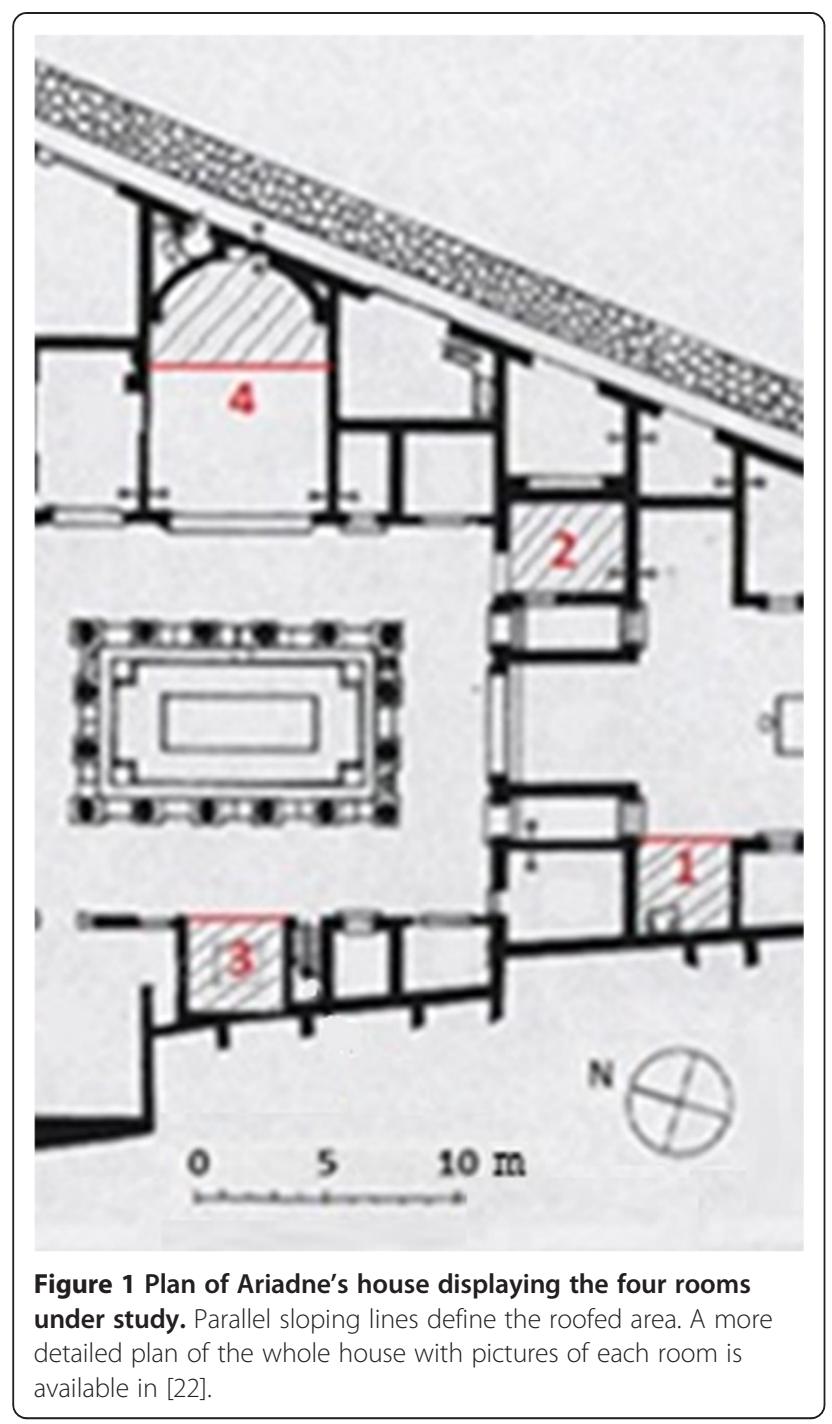

study in this season. The monitoring period started on July $20^{\text {th }} 2010$ and ended on September $15^{\text {th }} 2010$, resulting a frame of 58 days.

Each temperature data-logger was paired with a $\mathrm{RH}$ data-logger by means of a PVC structure. This assembly will be referred to hereafter as thermohygrometric probe (coded as \#1 to \#26 in Table 1). All probes were placed inside the 4 rooms under study except \#1, which was located on the top of an outside wall to serve as a control. Unfortunately, data-loggers of probes \#1 and \#2 were wrongly programmed and they were disregarded.

Data recorded in 2008 and 2010 can only be directly compared in the case of similar thermohygrometric conditions outside the rooms. Meteorological data from a weather station in Pompeii would be necessary to check this issue. Unfortunately, the closest stations are located in Naples and Capri, too far away. Given that room 4 was the only one that maintained the same roof, probes located there (\#3 and \#4) can be used as a reference to compare ambient conditions in both years. Figure 2 shows the average trajectories of temperature in room 4 for the monitored period of 58 days. In this period, the mean temperature was $27.8^{\circ} \mathrm{C}$ in 2008 and $26.2^{\circ} \mathrm{C}$ in 2010. The fact that summer 2008 was hotter may lead to a misinterpretation of data from probes in rooms 1-3. Thus, it is not possible to conclude if the observed differences of temperature in rooms 1-3 are caused by the roof change or are due to the different outside temperatures of each year, which implies that both effects are confounded.

Attempting to avoid this confusion of effects, it was decided to select a time frame of the monitoring period with a similar average temperature in both years inside room 4. The interval chosen was August $14^{\text {th }}$ to $31^{\text {st }}(18$ days), as indicated in Figure 2. For probes in room 4, Figure $3 \mathrm{a}$ shows that the mean diurnal evolution of temperature in the 18-day period was nearly the same in 2008 and 2010. Moreover, the average RH was also similar in both years (Figure 3c). Thus, it was assumed that outside ambient conditions were similar in this time frame of both years. Data out of this interval were disregarded.

The time series recorded by each data-logger reflects the evolution of the measured parameter versus time, and it is commonly denoted as trajectory. By carefully inspecting all trajectories recorded in 2008, it was reported in the previous study [24] that certain probes underwent abnormal peaks of temperature at particular time frames, which was caused by solar radiation incident on the probes. Trajectories obtained in 2010 were also visually examined, and only probe \#15 yielded a typical temperature peaks from about 5:00 PM to 8:00 PM caused by sunshine entering through the entryway of room 2 . The abnormal data were removed.

\section{Mean daily trajectories}

The average daily trajectories recorded by data-loggers in the selected 18-day period are displayed in Figure 3, which provides useful information to discuss the effect of roof change on thermohygrometric conditions. Minimum temperatures of each probe were similar in both years, but the maximum values in rooms 1-3 were obtained in 2008 . Similarly, trajectories of $\mathrm{RH}$ are also more pronounced in 2008. The microclimate was less hot and less dry after the roof change, which is more favorable from a preservation standpoint.

There is a lack of consensus about the ideal or limit values of thermohygrometric parameters for an optimum maintenance of frescoes. The Italian standard DM 10/2001 [27] indicates reference values for the conservation of cultural heritage. It does not provide guidelines for outdoor paintings, but nonetheless the admissible values suggested 
Table 1 Position of thermohygrometric probes

\begin{tabular}{|c|c|c|c|c|c|c|c|}
\hline Code & Height $^{a}$ & Room & Pictures ${ }^{b}$ & Code & Height $^{a}$ & Room & Pictures $^{\mathbf{b}}$ \\
\hline \#3 & 153 & 4 & $3^{\text {th }}, 4^{\text {th }}$ at L29 & \#15 & 30 & 2 & $7^{\text {th }}$ at L12 \\
\hline \#4 & 290 & 4 & & $\# 16$ & 0 & 2 & $12^{\text {th }}$ at $\mathrm{L} 13$ \\
\hline \#5 & 0 & 3 & $1^{\text {st }}$ at L18 & $\# 17$ & 338 & 2 & $4^{\text {th }}, 5^{\text {th }}, 8^{\text {th }}$ at $L 13$ \\
\hline \#6 & 0 & 3 & $1^{\text {st }}$ at $L 18$ & $\# 18$ & 300 & 2 & $7^{\text {th }}, 10^{\text {th }}$ at L12 \\
\hline \#7 & 163 & 3 & $1^{\text {st }}, 6^{\text {th }}$ at $\mathrm{L} 18$ & $\# 19$ & 310 & 2 & $7^{\text {th }}, 9^{\text {th }}$ at $L 12$ \\
\hline \#8 & 0 & 3 & $1^{\text {st }}, 2^{\text {nd }}, 3^{\text {rd }}$ at L18 & \#20 & 290 & 2 & $7^{\text {th }}$ at $L 12$ \\
\hline$\# 9$ & 189 & 3 & $1^{\text {st }}, 3^{\text {rd }}, 6^{\text {th }}$ at $L 18$ & \#21 & 175 & 1 & $2^{\text {nd }}, 3^{\text {rd }}, 17^{\text {th }}$ at $L 6$ \\
\hline$\# 10$ & 340 & 3 & $1^{\text {st }}, 6^{\text {th }}$ at L18 & \#22 & 240 & 1 & $3^{\text {rd }}, 11^{\text {th }}, 12^{\text {th }}$ at $\mathrm{L} 6$ \\
\hline \#11 & 0 & 3 & $1^{\text {st }}, 8^{\text {th }}$ at L 18 & \#23 & 330 & 1 & $3^{\text {rd }}, 15^{\text {th }}$ at $\mathrm{L} 6$ \\
\hline$\# 12$ & 210 & 3 & $6^{\text {th }}, 8^{\text {th }}$ at L18 & \#24 & 117 & 1 & $2^{\text {nd }}, 3^{\text {rd }}, 15^{\text {th }}$ at $L 6$ \\
\hline \#13 & 0 & 2 & $11^{\mathrm{h}}$ at $\mathrm{L} 13$ & \#25 & 54 & 1 & $3^{\text {rd }}, 10^{\text {th }}, 15^{\text {th }}$ at $L 6$ \\
\hline$\# 14$ & 0 & 2 & $2^{\text {nd }}$ at L13 & \#26 & 15 & 1 & $10^{\text {th }}, 11^{\text {th }}, 13^{\text {th }}$ at L6 \\
\hline
\end{tabular}

${ }^{a}$ Distance to the ground level in $\mathrm{cm}$. Probes \#6, \#8 and \#11 were covered with a ceramic tile that can be seen in [22]. Probe \#5 was located inside the glass box displayed in lodging 18 of [22].

bictures in [22] showing the exact position. For example, probe \#7 appears in the $1^{\text {st }}$ and $6^{\text {th }}$ pictures displayed in [22] after following the link of lodging 18 (L18), which is coded as room 3 in Figure 1. Lodgings (L) numbered as 6, 12 and 29 in the room plan of [22] (coded here as L6, L12 and L29) correspond to rooms 1, 2 and 4, respectively. The link to lodging 13 (L13) in [22] also shows pictures of room 2.

by this standard for indoor mural paintings (RH: $45-60 \%$ and temperature: $6-25^{\circ} \mathrm{C}$ ) can be taken as a reference for the present work.

Figures $3 \mathrm{c}$ and $3 \mathrm{~d}$ show that $\mathrm{RH}$ values below $45 \%$ were recorded at midday in rooms $1-3$ in 2008. By contrast, such dry conditions did not occur in 2010 except in room 3. Thus, the roof change has avoided the low $\mathrm{RH}$ registered in 2008 that could be regarded as harmful for the frescoes according to [27].

The daily variation of temperature (DVT) for a given day was computed as the difference of the maximum $\left(\mathrm{T}_{\max }\right)$ and minimum $\left(\mathrm{T}_{\min }\right)$ recorded values. It is well known that DVT should be kept as low as possible for an optimum conservation of wall paintings. DVT was calculated for the 18 days under study (Figure 4). In 2010, the most stable conditions (i.e., lowest DVT) were found in rooms 2 and 4 as well as floor sensors (DVT $\approx 7^{\circ} \mathrm{C}$ ). Room 4 also yielded a similar DVT in 2008 because the roof was maintained and the 18-day time frame was properly chosen to achieve an equal mean temperature in this room for both years.

In 2008, the lowest DVT was achieved in room 4, while data-loggers in room 2 and those on the floor yielded a DVT $=10.2^{\circ} \mathrm{C}$. Thus, DVT underwent a reduction of about $4^{\circ} \mathrm{C}$ in room 2 caused by the roof change, becoming the lodging with better conditions for the frescoes. This room is delimited by four walls and presents a semi-confined environment more isolated from outside

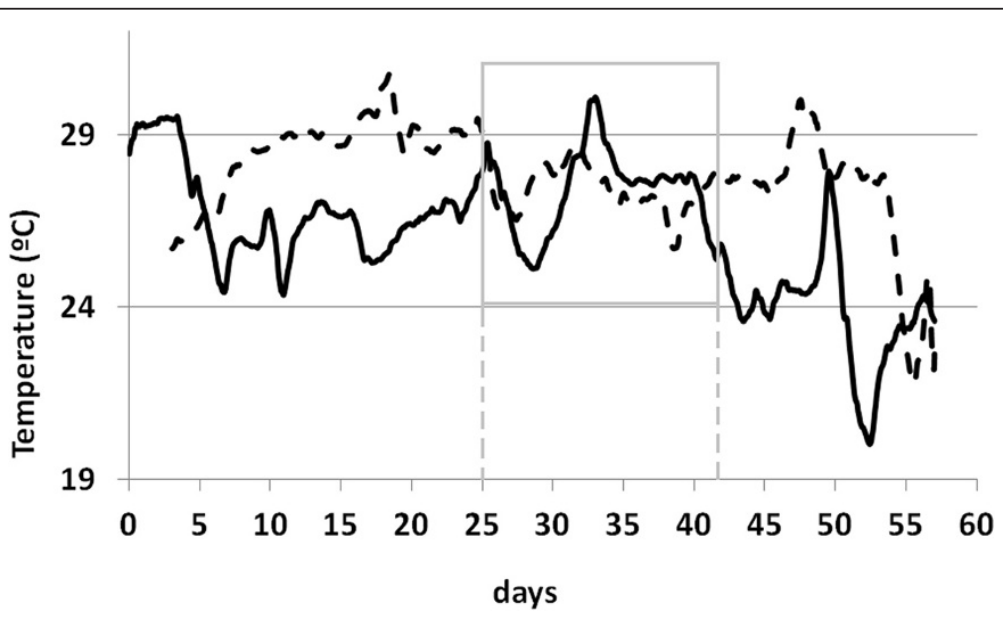

Figure 2 Average temperature in summer 2008 and 2010 recorded by data-loggers \#3 and \#4 (room 4). Day 0 corresponds to July $20^{\text {th }}$ 2008 (dashed trajectory) and July $20^{\text {th }} 2010$ (continuous). A moving average with a window size of 48 data (i.e., one day) was applied to smooth both time series. The time frame from day 25 to 42 (highlighted in gray color) presents a similar average temperature in both years. 


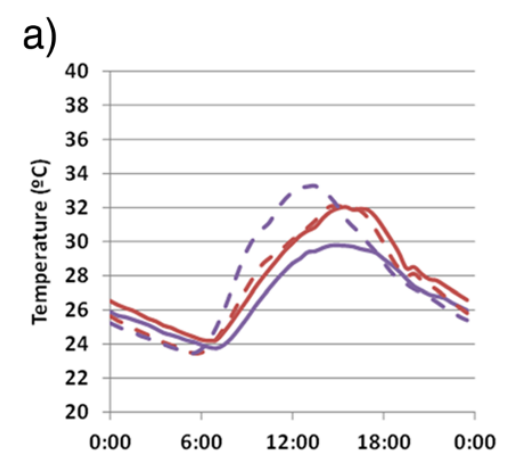

b)

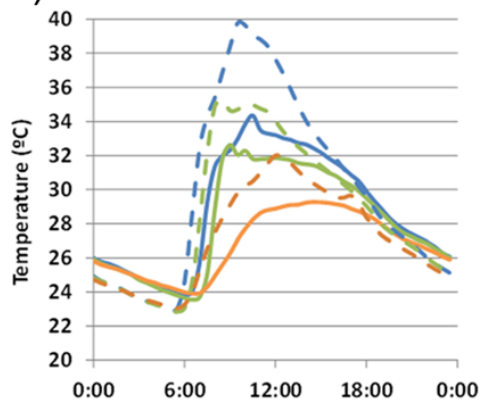

c)

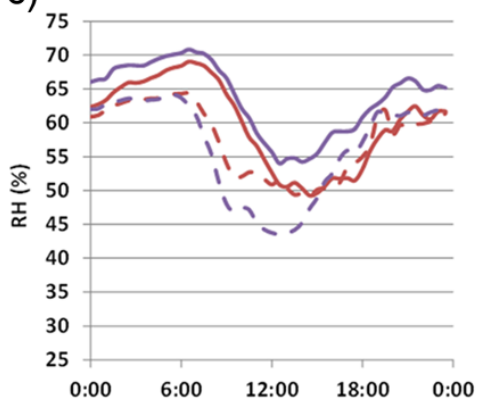

d)

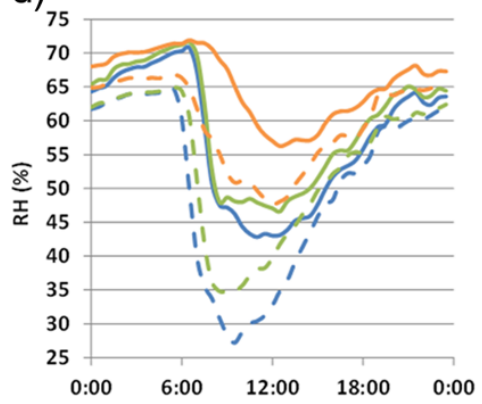

Figure 3 Mean daily trajectories of temperature and RH in summer. Figures $(\mathbf{a}, \mathbf{b})$ depict temperature trajectories and $(\mathbf{c}, \mathbf{d}) \mathrm{RH}$ trajectories. Monitoring period: 14-31 August 2008 (dashed trajectories); 14-31 August 2010 (continuous). Trajectories were averaged for all data recorded in each room except by floor probes. Color codes: green (probes in room 1: \#21 - \#26); violet (room 2: \#15, \#17 - \#20); blue (room 3: \#7, \#9, \#10, $\# 12)$; red (room 4: \#3, \#4); orange (floor probes: \#6, \#8, \#11,\#13,\#14,\#16). The probe inside the mosaic glass box (\#5) was not considered here.

fluctuations, which would explain its low DVT in 2010. DVT was $15.1^{\circ} \mathrm{C}$ (room 1 ) and $18.5^{\circ} \mathrm{C}$ (room 3) in 2008 , but it decreased to $12.3^{\circ} \mathrm{C}$ in 2010 . Although this reduction is favorable from a preservation viewpoint, there is still a need to achieve a further decrease of DVT, trying to reach the microclimate of room 2 . One option would be to insulate the roof with spray polyurethane foam. Another alternative, though more expensive, is to replace the undulating fiber cement sheets currently covering rooms $1-3$ by foam-filled insulated roof sheets.

Although DVT is a good parameter to evaluate the effect of roof change, the opaque shelter has decreased the temperature in rooms 1 and 3 (Figure 3b) probably due to the different solar radiation incident on the walls through the roof. Preliminary measurements of direct light radiation were carried out in 2008 [23], and a detailed study about indirect light radiation in the rooms with the new coverage will be addressed as part of the on-going conservation project.

Results indicate that the roof change has improved the conditions for the preservation of wall paintings, but not enough. The goal would be to achieve a microclimate in rooms 1 and 3 similar to that in room 2. Thus, a general recommendation to reduce the deterioration of Pompeian frescoes in other houses would be to cover the lodgings with opaque roofs, preferentially containing thermal insulation. Another useful measure would be to avoid direct contact of sunshine radiation in summer by installing some kind of vertical curtains, shades or microperforated fabrics as a parapet hanging on the roof edge.

Probe \#5 was installed inside the glass box protecting the mosaic in room 3. In 2008, the glass received direct sunshine through the transparent roof, causing a severe greenhouse effect with DVT up to $25^{\circ} \mathrm{C}$ (Figure 5), which is extremely harmful. This effect was eliminated with the roof change, resulting a DVT of about $7^{\circ} \mathrm{C}$, which is similar as in the case of floor probes (Figure 4).

\section{Analysis of variance (ANOVA)}

In order to further study the effect of roof change, different parameters were calculated for each $\mathrm{RH}$ data-logger and each day in both periods under study (14-31 August): maximum $\left(\mathrm{RH}_{\max }\right)$, minimum $\left(\mathrm{RH}_{\min }\right)$ and average. Daily averages of temperature, $T_{\max }$ and $T_{\min }$ values were computed as well. Different ANOVAs were carried out considering two factors: data-logger and year.

An effect of sensor height in room 2 is reflected by Figure 6a. Floor probes recorded lower temperatures with a similar mean in both years. By contrast, probes at the upper position (\#17 - \#20) registered higher values in 2008 due to the effect of solar radiation incident on the upper parts of walls before the roof change. The observed 


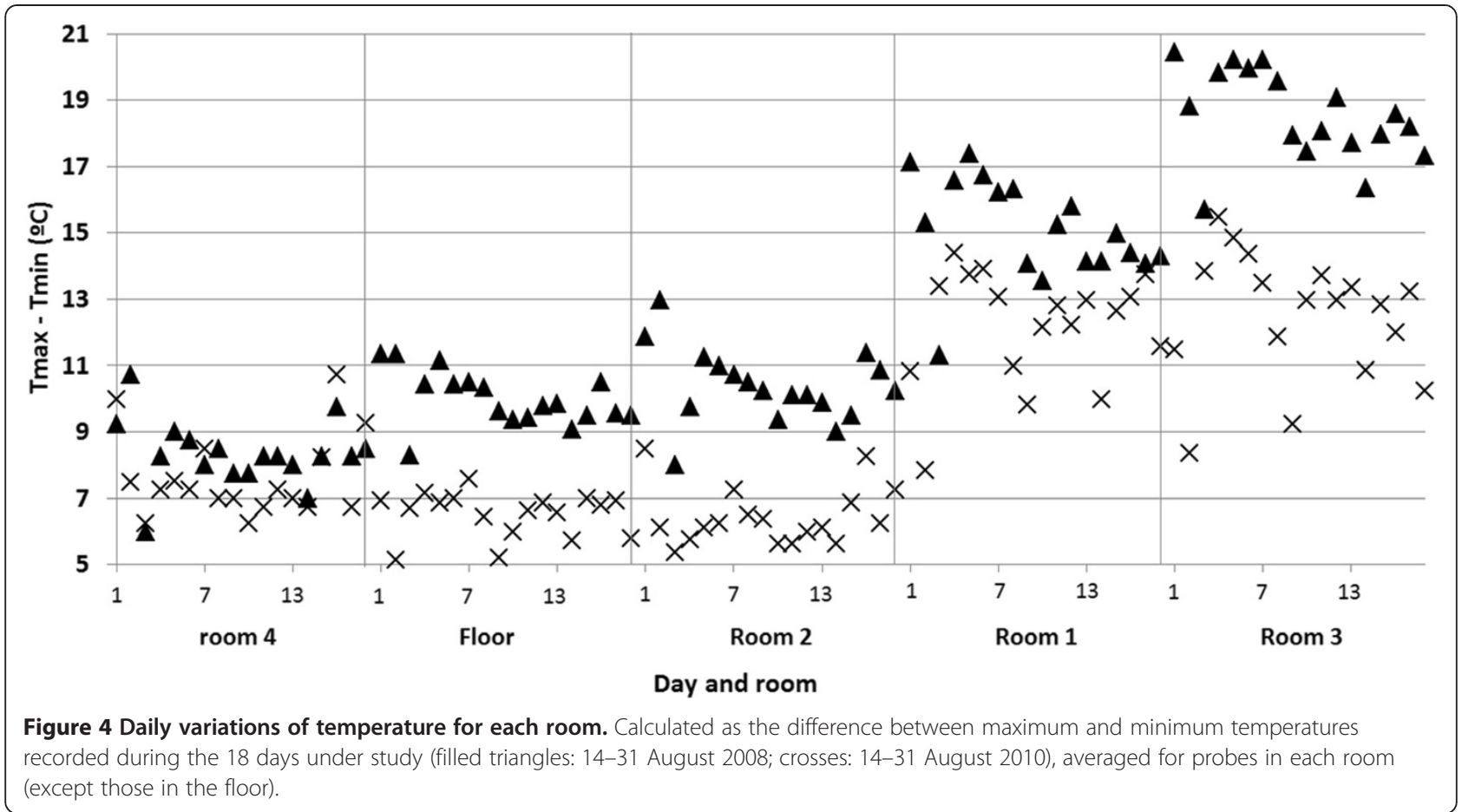

differences are statistically significant $(\alpha=0.05)$ because the LSD (Least Significant Difference) intervals do not overlap. The pattern of temperature according to sensor height is inversely related to the pattern of RH (Figure 6b) because higher temperatures imply lower $\mathrm{RH}$ and vice-versa. The observed differences of $\mathrm{RH}$ according to year are also statistically significant. Such clear effect of sensor height on thermohygrometric parameters is not so apparent in the other lodgings probably because room 2 is the only one delimited by four walls, which provides more stable conditions.

The $\mathrm{T}_{\max }$ (averaged for the 18-day period) of probes in rooms 1 and 3 is shown in Figures $7 \mathrm{a}$ and $7 \mathrm{~b}$, respectively. This parameter is remarkably different among probes in room 3 , ranging from $31.5^{\circ} \mathrm{C}(\# 11)$ to $49.1^{\circ} \mathrm{C}$ (\#9) in 2008 (Figure 7b). Such variability represents a serious risk for conservation purposes [27]. No significant differences between 2008 and 2010 are observed in probes that recorded the lowest $\mathrm{T}_{\max }$ values (\#6, \#11, $\# 12$, \#24, and \#25). All of these data-loggers (except \#6) are located on walls facing to the north, which is the orientation receiving less solar radiation. By contrast, the highest $\mathrm{T}_{\max }$ values, particularly in 2008 , were basically recorded by sensors facing to the south (\#8, \#9 and \#21). The reduction of solar radiation incident on walls due to the opaque shelter has decreased $\mathrm{T}_{\max }$ in rooms 1 and 3 (\#8, \#9, \#10, and \#21), particularly in those positions that received more sunshine.
The change of shelter has also produced a slight increase of $\mathrm{T}_{\min }$ in about $0.6^{\circ} \mathrm{C}$ in rooms 1 and 3 (Figure 8). The differences are not statistically significant for all probes because some LSD intervals overlap, but the parallel trend is apparent in both rooms. The decrease of $T_{\max }$ caused by the roof change and the slight increase of $\mathrm{T}_{\text {min }}$ results in a lower DVT in 2010 (Figure 4), which involves that the microclimate was more stable throughout the day and, hence, more appropriate for conservation purposes.

\section{Bivariate plots}

Figure 9a displays a scatterplot of $\mathrm{T}_{\max }$ in $2010 \mathrm{vs}$. $\mathrm{T}_{\max }$ in 2008. Probes \#3 and \#4 appear on the bisector line (i.e., equal mean values in both years), which indicates that the 18-day period was correctly selected. Some additional probes are also close to the bisector, but most of them yielded a lower $T_{\max }$ in 2010 as discussed above. The high $\mathrm{T}_{\max }$ of \#9, \#10 or \#21 is also reflected in Figure 7, but Figure 9a provides complementary information because all probes are depicted. The bivariate plot of $\mathrm{T}_{\min }$ in 2010 vs. $\mathrm{T}_{\min }$ in 2008 (Figure 9b) is consistent with Figure 8 and reveals that $\mathrm{T}_{\text {min }}$ was about $0.6^{\circ} \mathrm{C}$ higher in 2010 on average compared with 2008 , except in the case of room 2 with $0.3^{\circ} \mathrm{C}$ of variation.

$\mathrm{RH}$ and temperatures measured during one day by a given probe were negatively correlated according to Figure 3 because the maximum temperatures recorded at midday correspond to the minimum RH. Moreover, 


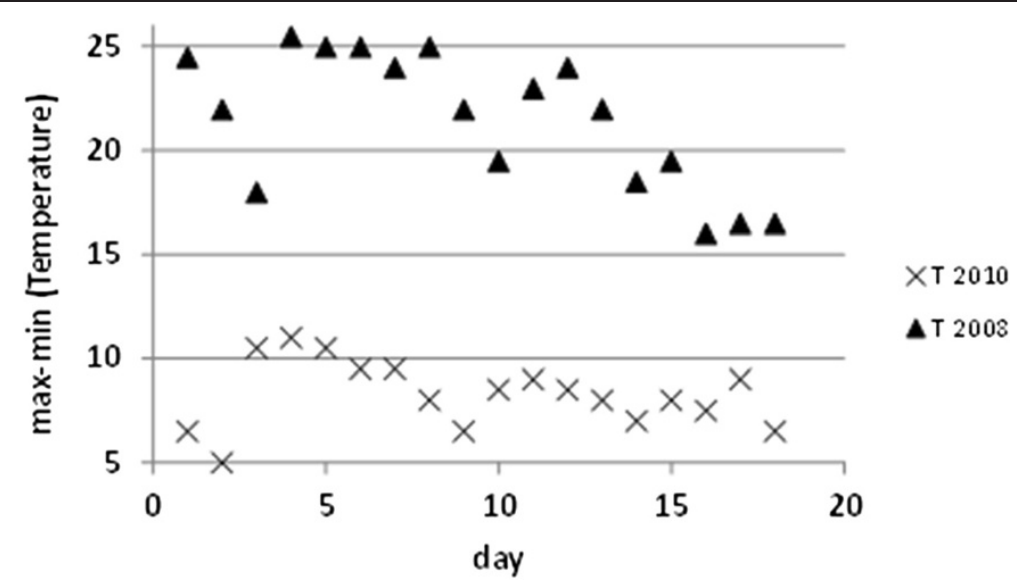

Figure 5 Daily variations of temperature for data-logger \#5 (mosaic). Difference between maximum and minimum temperatures recorded during 18 days (filled triangles: 14-31 August 2008; crosses: 14-31 August 2010).

probes that yielded the highest temperatures $\left(\mathrm{T}_{\max }\right)$ also recorded the lowest $\mathrm{RH}\left(\mathrm{RH}_{\text {min }}\right)$, which was also reported in the previous study [24]. This inverse relationship between $\mathrm{T}_{\max }$ and $\mathrm{RH}_{\min }$ shows up by comparing Figures $9 \mathrm{a}$ and 10a because the relative position of probes in both figures is basically the same. There is also certain similarity between $\mathrm{T}_{\min }$ (Figure $9 \mathrm{~b}$ ) and $\mathrm{RH}_{\max }$ (Figure $10 \mathrm{~b}$ ).

In 2010, half of the probes registered $\mathrm{RH}_{\text {min }}$ values above $45 \%$, but only two probes (\#13 and \#14) satisfied this condition in 2008 (Figure 10a). Taking into account that $45-60 \%$ is the recommended range of $\mathrm{RH}$ according to [27] for mural paintings, this result implies that the change of roof has improved the $\mathrm{RH}$ conditions from a conservation standpoint. In the case of $\mathrm{RH}_{\max }$ (Figure 10b), the points follow a linear trend, and it can be deduced that $\mathrm{RH}$ increased around 6 units in 2010 with respect to 2008 .
Probe \#5 was affected by a severe greenhouse effect in 2008 that is no longer present in 2010, but it behaves as an outlier in Figures 9b and 10b, with an abnormal low $\mathrm{RH}_{\max }$ and a high $\mathrm{T}_{\text {min }}$. The interpretation is uncertain because \#5 was the only probe inside the glass box protecting the mosaic. The microclimate inside this box is totally confined and cannot be directly compared with ambient conditions in the rooms.

\section{Efficiency of transparent vs. opaque shelters}

A list of 222 covered archaeological sites in Italy is available in the literature (see annex of [26]), 38.7\% of which are regarded as shelters with an intermediate efficiency and $59 \%$ as highly efficient. The tile roof of room 4 appears in this list as highly efficient, with a score of 7.1 on a $0-10$ scale, while transparent shelters covering the other rooms scored 5.5 (intermediate). However, these a)

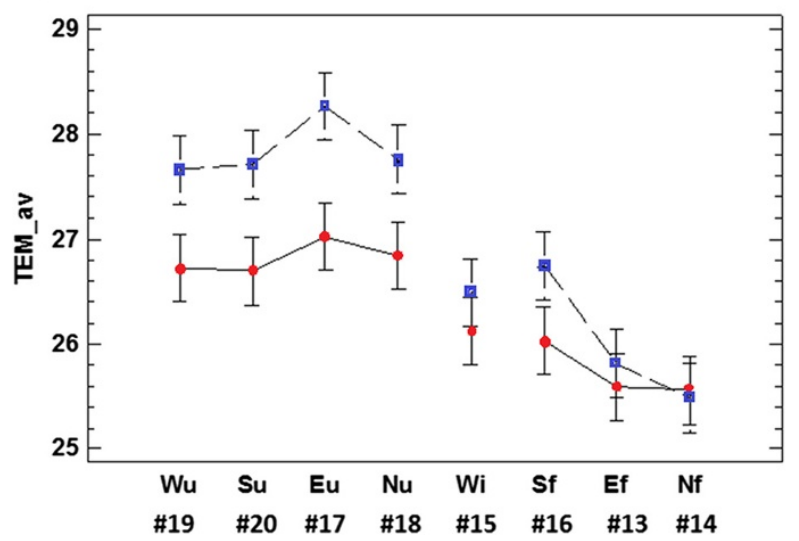

b)

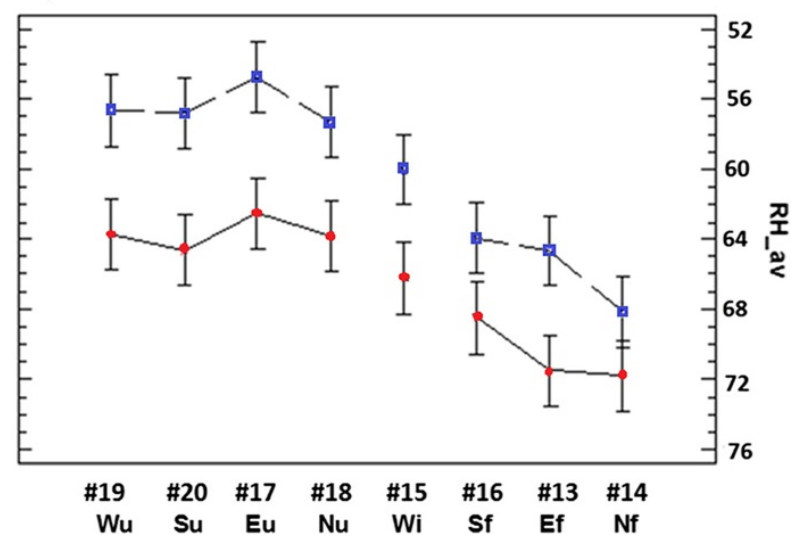

Figure 6 ANOVA results (room 2): interaction plot. Plot showing the effect of year (2008: blue squares; 2010: red circles) and data-logger on the daily mean temperatures (a) and RH (b) recorded in room 2 from $14^{\text {th }}$ to $31^{\text {st }}$ of August. Codes indicate the wall orientation (North, South, East or West) and the height (u: upper position; i: intermediate; f: floor level). For each data-logger, the average and 95\% LSD interval is illustrated. 


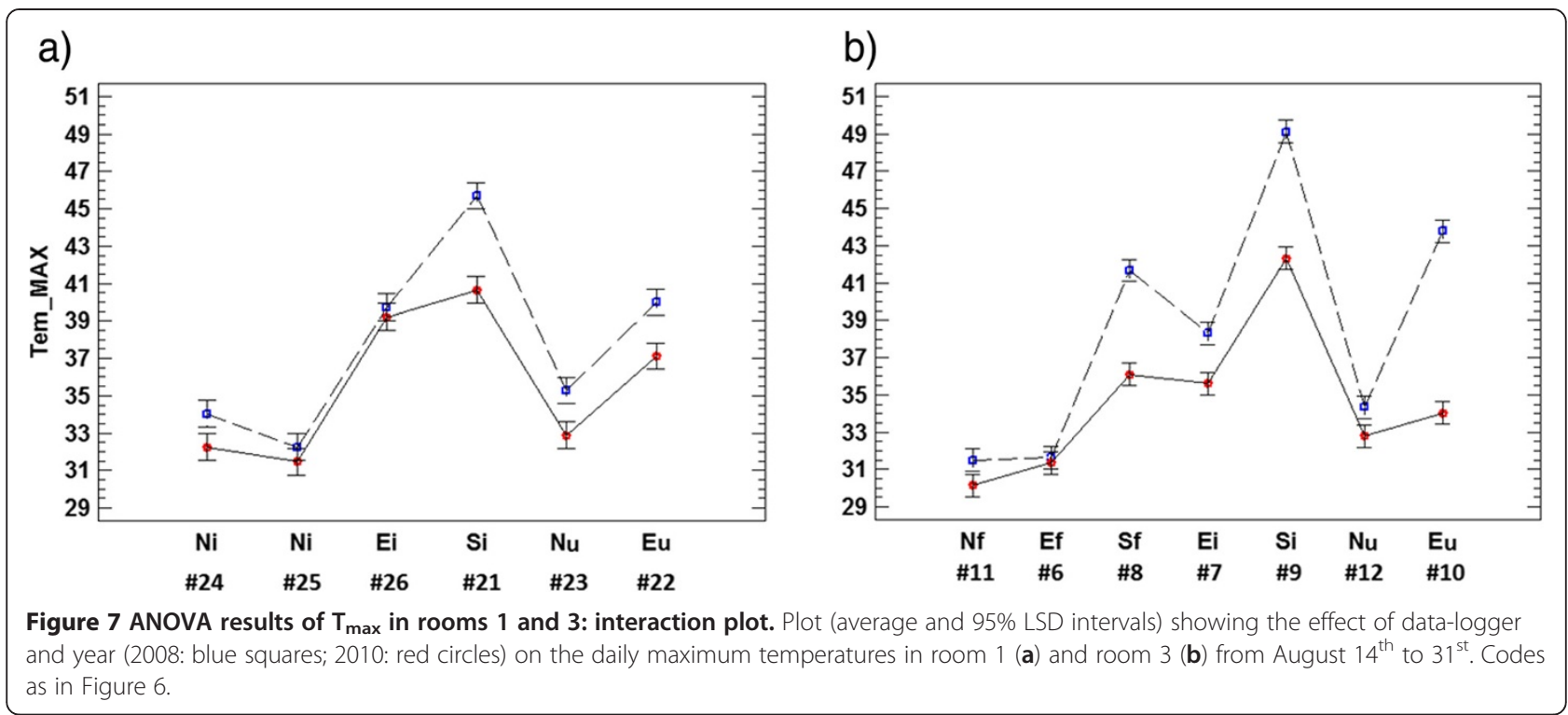

scores were calculated using qualitative criteria not based on microclimate studies. In our opinion, such efficiency index may provide a rough guidance for archaeological sites curators, but it could be improved by taking into consideration parameters derived from multivariate microclimate monitoring studies. The present work may provide guidelines for a methodology aimed at comparing the efficiency of shelters in different locations.

\section{Experimental}

\section{Description and installation of data-loggers}

The same set of RH and temperature data-loggers (models Hygrochron DS1923 [28] and Thermochron DS1922L [29], respectively) used in the previous study [24] was re- installed in Ariadne's house in July 2010. According to the manufacturer (Maxim Integrated Products, Inc., Sunnyvale, CA), the accuracy is $\pm 5 \% \mathrm{RH}$ [28]. All dataloggers were calibrated prior to their installation in 2008 as described in [24]. Based on the calibration experiment, it was obtained that the temperature biases ranged from $-0.44^{\circ} \mathrm{C}$ to $+0.53^{\circ} \mathrm{C}$ (see Table 1 of [24]), which is nearly coincident with the accuracy range $\left( \pm 0.5^{\circ} \mathrm{C}\right)$ indicated by the manufacturer [28]. These biases were corrected as described in [24] to improve the accuracy of temperature measurements. Another calibration experiment was carried out in 2010 with RH sensors by comparing their measurements with reference values of a standard procedure based on aqueous solutions of two salts $(\mathrm{NaCl}$ and $\mathrm{LiCl})$
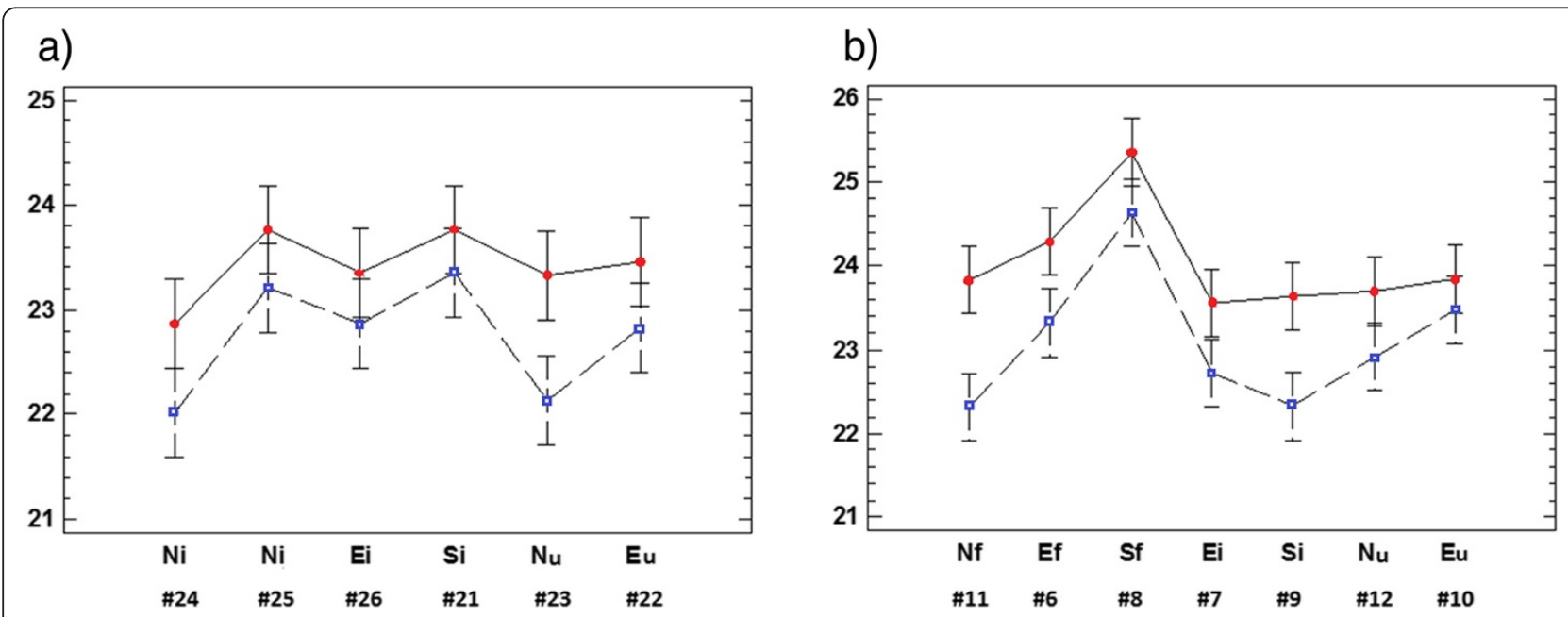

Figure 8 ANOVA results of $T_{\min }$ in rooms 1 and 3: interaction plot. Plot of factors data-logger and year (2008: blue squares; 2010: red circles) on the daily minimum temperatures in room 1 (a) and room 3 (b). Codes as in Figure 6. 


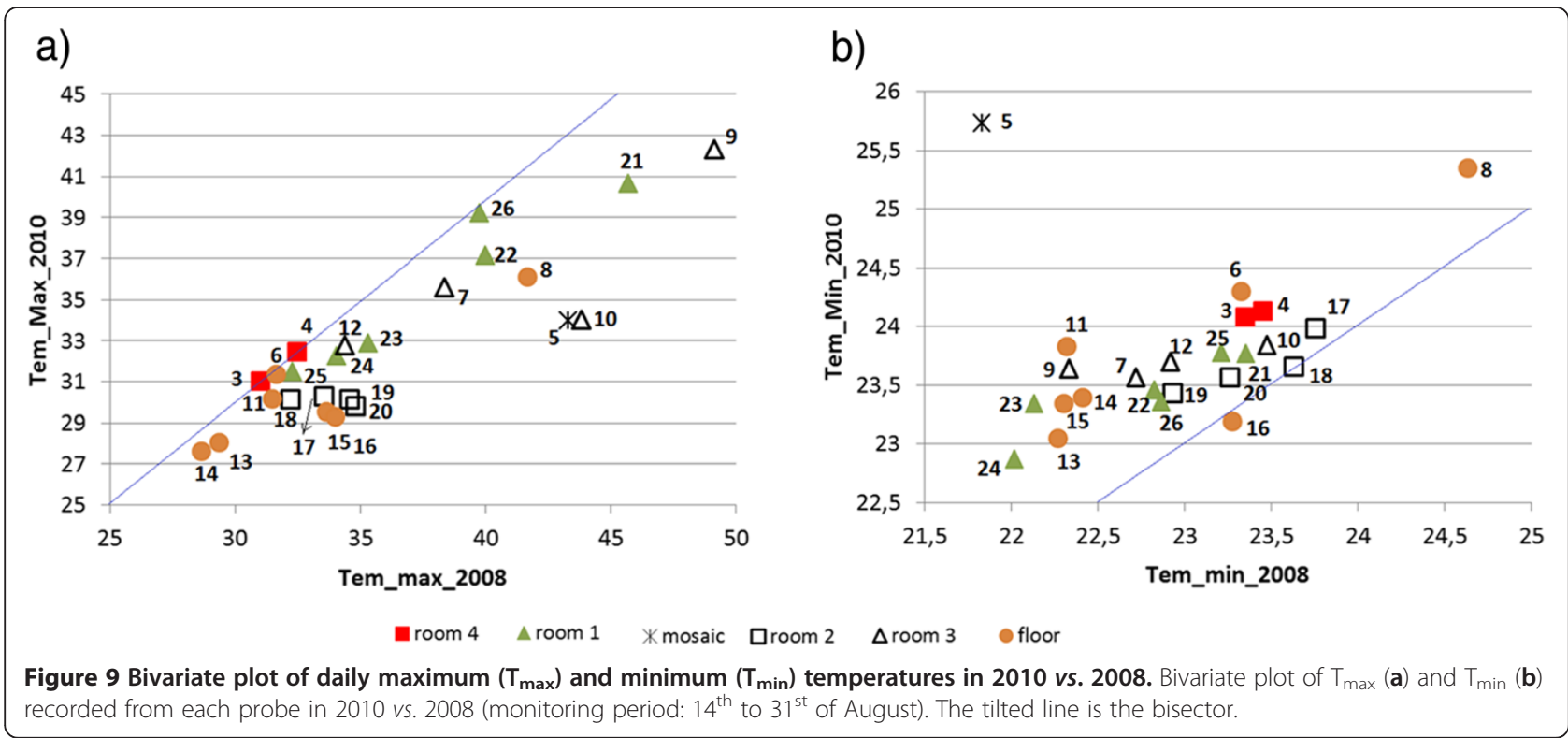

[30], resulting a bias below $1 \%$ for all data-loggers. $\mathrm{RH}$ recordings were corrected taking into account the experimental biases to improve the accuracy.

Each probe was composed of one pair of DS1923 and DS1922L data-loggers assembled together by means of a PVC protective structure with a cylindrical shape $(6 \mathrm{~cm}$ of diameter), which allows a convenient fixing to the wall. One measurement was recorded from each datalogger every 30 minutes, which involves 48 recordings per day. All probes were placed in the same positions as in the monitoring experiment of 2008 [24] in order to allow an appropriate data comparison of both years. The purpose was to locate data-loggers in the four rooms at three levels: floor $(0-15 \mathrm{~cm})$, intermediate $(<2 \mathrm{~m})$ and upper position ( $>2 \mathrm{~m}$ ) (Table 1 ).

\section{Statistical data analysis}

Firstly, we computed the mean values recorded in 2010 by each data-logger at 0:00, 0:30, 1:00... and so on until 12:00 PM, resulting a daily mean trajectory. The calculation was performed with the set of 18 days under study (14-31 August), which were selected to achieve an equal mean temperature in room 4 in both years. All trajectories were visually inspected in order to detect abnormal peaks as those identified in the previous study [24]. Next, trajectories of probes in the same room were
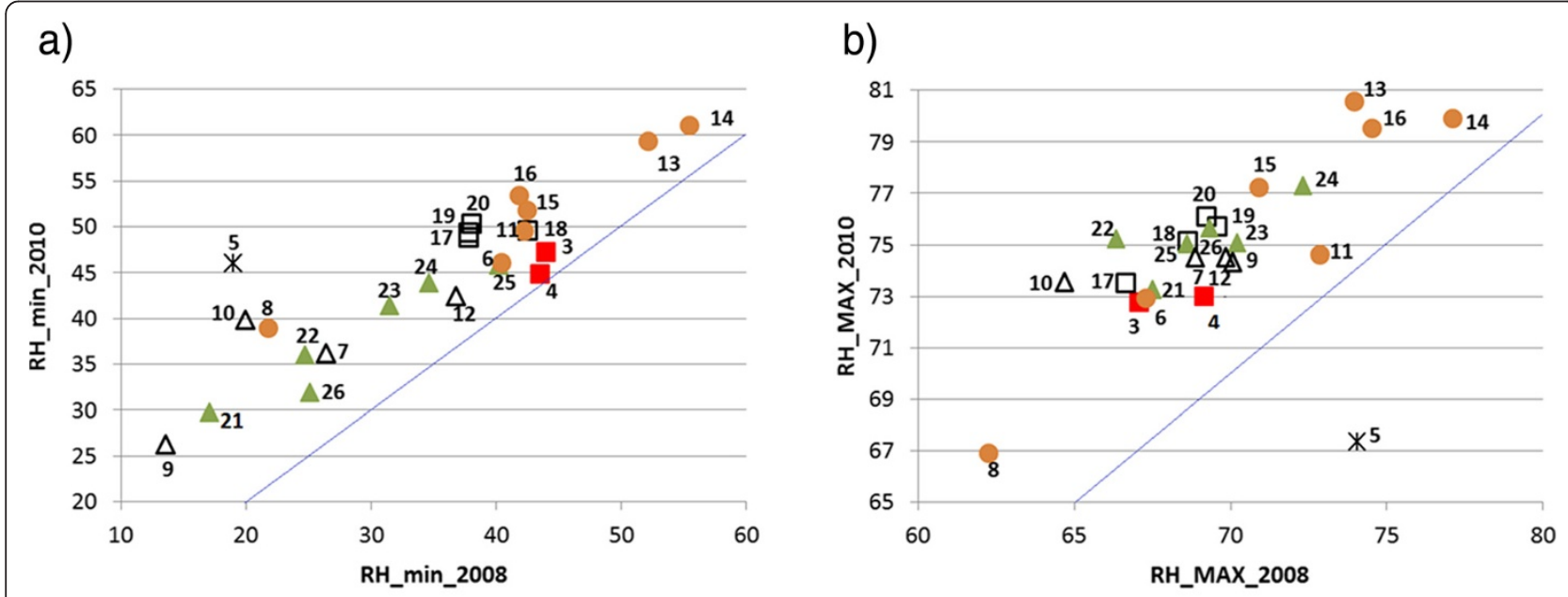

room $4 \Delta$ room $1 *$ mosaic $\square$ room $2 \Delta$ room 3 floor

Figure 10 Bivariate plot of daily minimum $\left(\mathrm{RH}_{\min }\right)$ and maximum $\left(\mathrm{T}_{\text {max }}\right)$ relative humidities in 2010 vs. 2008. Bivariate plot of $\mathrm{RH}$ min (a) and $\mathrm{RH}_{\max }$ (b) recorded from each probe in 2010 vs. 2008 (14 ${ }^{\text {th }}$ to $31^{\text {st }}$ of August). The tilted line is the bisector. 
averaged, except those on the ground that were set aside (Figure 3). This procedure was also applied to data recorded in the same time frame of 2008, and the differences were discussed.

For each day and probe, the following parameters were computed: mean temperature, mean $\mathrm{RH}, \mathrm{T}_{\max }, \mathrm{T}_{\min }$, $\mathrm{RH}_{\max }$, and $\mathrm{RH}_{\text {min }}$. One important parameter frequently considered in the conservation of cultural heritage [27] is the daily variation of temperature (i.e., $\mathrm{T}_{\max }-\mathrm{T}_{\min }$ ). This parameter was computed for the 18-day period of each year and it was averaged for probes in the same room, which provides useful information about the effect of roof change (Figure 4). In order to study if the differences among probes in the same room were statistically significant, different multifactor ANOVAs were performed with the key thermohygrometric parameters considering two factors: year (2008 or 2010) and probes (Figures 6, 7, 8). All ANOVA models were carried out with the software Statgraphics 5.1 [31].

Attempting to further characterize the differences among probes according to year, different bivariate plots (Figures 9 and 10) were obtained with $\mathrm{T}_{\max }, \mathrm{T}_{\min }, \mathrm{RH}_{\max }$, and $\mathrm{RH}_{\text {min }}$ (averaged for the 18 days). They provide further information about the relationship between $\mathrm{RH}$ and temperature. $\mathrm{RH}$ values were discussed according to the guidelines for indoor mural paintings indicated by the Italian standard DM 10/2001 [27].

\section{Conclusions}

The statistical analysis has revealed a considerable reduction of about $3.5^{\circ} \mathrm{C}$ in the maximum daily values reached in summer at rooms 1 and 3 caused by the roof change. Results show that this corrective measure adopted in 2009 has lowered the maximum temperatures and has also increased the $\mathrm{RH}$ and minimum temperatures, which entails an attenuation of daily variations of thermohygrometric conditions. Thus, the roof change has created a microclimate more stable and less harmful for the conservation of frescoes.

The steadiest ambient conditions were found in room 2 , which is intuitively appealing because this room is delimited by four walls and the microclimate inside is more isolated from outdoor fluctuations. The roof change has enhanced the conditions in rooms 1 and 3 from a preservation standpoint, but they can be further improved to resemble those in room 2. For this purpose, several additional corrective measures are proposed.

An effect of sensor height was detected in room 2 . The higher temperatures recorded there at the upper positions were due to diffuse solar radiation incident on walls through the transparent roof in 2008. In rooms 1 and 3, it was also found that sensors facing to the south recorded higher temperatures particularly in 2008, probably because the south orientation received more solar radiation before the roof change.

The methodology of data analysis applied here is also of interest for similar studies aimed at comparing thermohygrometric data recorded in different periods, because it is necessary to avoid the confusion of effects that appears when the average conditions of the periods are different.

\section{Competing interests}

The authors declare that they have no competing interests.

\section{Authors' contributions}

All authors contributed equally to this work. PM is a researcher developing a $\mathrm{PhD}$ thesis about statistical monitoring for preventive conservation of cultural heritage; FJGD was responsible for the design of probes and their implementation, and MZ provided statistical assistance with the data analysis. All authors read and approved the final manuscript.

\section{Acknowledgements}

This work was partially supported by the Spanish Government (Ministerio de Ciencia e Innovación) under projects HAR2010-21944-C02-01 and HAR2010-21944-C02-02.

\section{Author details}

'Department of Applied Physics (UD Agriculture Engineering), Universitat Politècnica de València, Camino de Vera s/n, Valencia 46022, Spain. ${ }^{2}$ Valencian Institute for Conservation and Restoration of Cultural Heritage, C/ Genaro Lahuerta 25-3․ Valencia 46010, Spain. ${ }^{3}$ Center of Physical Technologies, Associated Unit ICMM-CSIC/UPV, Universitat Politècnica de València, Av de los Naranjos s/n, Valencia 46022, Spain. ${ }^{4}$ Department of Applied Statistics, Operations Research and Quality, Universitat Politècnica de València, Camino de Vera s/n, Valencia 46022, Spain.

Received: 30 November 2012 Accepted: 13 May 2013 Published: 17 May 2013

\section{References}

1. De los Rios A, Cámara B, García del Cura MA, Rico VJ, Galván V, Ascaso C: Deteriorating effects of lichen and microbial colonization of carbonate building rocks in the Romanesque churches of Segovia (Spain). Sci Total Environ 2009, 407:1123-1134.

2. Cooke RU, Smalley IJ: Salt weathering in deserts. Nature 1968, 220:1226-1227.

3. Paradise TR: Limestone weathering and rate variability, great temple of Amman, Jordan. Phys Geogr 1998, 19(2):133-146.

4. Winkler EM: Weathering rates as exemplified by Cleopatra's needle in New York city. J Geol Educ 1965, 13:50-52.

5. Winkler EM: Important agents of weathering for building and monumental stone. Eng Geol 1966, 1:381-400.

6. Winkler EM, Wilhelm EJ: Salt burst by hydration pressures in architectural stone in urban atmosphere. Geol Soc Am Bull 1970, 81:567-572.

7. Nord AG: Efflorescence salts on weathered building stone in Sweden. Geol Fören Stock För 1992, 114(4):423-229.

8. Wüst RAJ, Schlüchter C: The origin of soluble salts in rocks of the Thebes mountains, Egypt: The damage potential to ancient Egyptian wall art. J Archaeol Sci 2000, 27(12):1161-1172.

9. Arnold A, Zehnder K: Monitoring wall paintings affected by soluble salts. In The Conservation of Wall Paintings. 2nd edition. Edited by Cather $S$. London: Courtauld Institute of Art and the Getty Conservation Institute; 1996:103-136

10. Lillie M, Smith R, Reed J, Inglis R: Southwest Scottish Crannogs: using in situ studies to assess preservation in wetland archaeological contexts. J Archaeol Sci 2008, 35(7):1886-1900.

11. Bernardi A: Microclimate in the British museum, London. Museum Manag Curat 1990, 9:169-182.

12. Bernardi A, Camuffo D: Microclimate in the chiericati palace municipal museum, Vicenza. Museum Manag Curat 1995, 14:5-18. 
13. Camuffo D, Bernardi A, Sturaro G, Valentino A: The microclimate inside the pollaiolo and Botticelli rooms in the Uffizi gallery, Florence. J Cult Herit 2002, 3:155-161.

14. Camuffo D, Sturaro G, Valentino A: Thermodynamic exchanges between the external boundary layer and the indoor microclimate at the basilica of Santa Maria Maggiore, Rome, Italy: the problem of conservation of ancient works of art. Bound-Lay Meteorol 1999, 92:243-262.

15. Tabunschikov Y, Brodatch M: Indoor air climate requirements for Russian churches and cathedrals. Indoor Air 2004, 14(Suppl 7):168-174.

16. García-Diego F-J, Zarzo M: Microclimate monitoring by multivariate statistical control: The renaissance frescoes of the Cathedral of Valencia (Spain). J Cult Herit 2010, 11(3):339-344.

17. Zarzo M, Fernández-Navajas A, García-Diego F-J: Long-term monitoring of fresco paintings in the Cathedral of Valencia (Spain) through humidity and temperature sensors in various locations for preventive conservation. Sensors 2011, 11(9):8685-8710

18. Nava S, Becherini F, Bernardi A, Bonazza A, Chiari M, García-Orellana I, Lucarelli F, Ludwig N, Migliori A, Sabbioni C, Udisti R, Valli G, Vecchi R: An integrated approach to assess air pollution threats to cultural heritage in a semi-confined environment: the case study of Michelozzo's courtyard in Florence (Italy). Sci Total Environ 2010, 408(6):1403-1413.

19. Maekawa S, Lambert F, Meyer J: Environmental monitoring at Tiwanaku. Mater Res Soc Symp Proc 1995, 352:885-892.

20. Pesando F: La Casa de Ariadna de Pompeya: redescubrimiento de una domus. In Pompeya bajo Pompeya, Las excavaciones en la Casa de Ariadna. Edited by Ribera A, Olcina M, Ballester C. Valencia: Fundación MARQ; 2007:21-24

21. Video describing Ariadne's House in Pompei. http://vimeo.com/3123842.

22. Pictures of Ariadne's House (Regio VII, Insula 4). [http://www. pompeiiinpictures.com].

23. Pérez MC, García Diego F-J, Merello P, D’Antoni P, Fernández Navajas A, Ribera-Lacomba A, Ferrazza L, Pérez Miralles J, Baró J-L, Merce P, D'Antoni H, Curiel Esparza J: Ariadne's house (Pompeii, Italy) wall paintings: A multidisciplinary study of its present state focused on a future restoration and preventive conservation. Mater Constr. doi:10.3989/ mc.2012.00812. in press.

24. Merello P, García-Diego F-J, Zarzo M: Microclimate monitoring of Ariadne's house (Pompeii, Italy) for preventive conservation of fresco paintings. Chem Central J 2012, 6:145.

25. Coperture: lastre in fibrocemento ecologico (Edilit SpA). http://www.edilit.com.

26. Laurenti MC (Ed): Le Coperture delle Aree Archeologiche. Roma: Museo Aperto. Gangemi editore; 2006.

27. DM 10/2001: Atto di Indirizzo sui Criteri Tecnico-scientifici e Sugli Standard di Funzionamento e Sviluppo dei Musei. Ministero per i Beni e le Attività Culturali. Rome (Italy): Gazzetta Ufficiale della Repubblica Italiana (Official Bulletin of Italian Republic); 2001. DL 112/1998 art. 150 comma 6.

28. Hygrochron Temperature/Humidity Logger iButton with 8KB Data-Log Memory. Maxim Integrated Products. [http://datasheets.maxim-ic.com/en/ds/DS1923.pdf].

29. Temperature Logger iButton with 8KB Data-Log Memory. Maxim Integrated Products. [http://datasheets.maxim-ic.com/en/ds/DS1922L-DS1922T.pdf].

30. ASTM E: 104-02: Standard Practice for Maintaining Constant Relative Humidity by Means of Aqueous Solutions. West Conshohocken, PA: ASTM Intl; 2012.

31. Statgraphics Software. [http://www.statgraphics.net]

doi:10.1186/1752-153X-7-87

Cite this article as: Merello et al:: Evaluation of corrective measures implemented for the preventive conservation of fresco paintings in Ariadne's house (Pompeii, Italy). Chemistry Central Journal 2013 7:87.

Publish with ChemistryCentral and every
scientist can read your work free of charge
"Open access provides opportunities to our
colleagues in other parts of the globe, by allowing
anyone to view the content free of charge."
W. Jeffery Hurst, The Hershey Company.
- available free of charge to the entire scientific community
- peer reviewed and published immediately upon acceptance
- cited in PubMed and archived on PubMed Central
- yours - you keep the copyright
Submit your manuscript here:
http://www.chemistrycentral.com/manuscript/

